\title{
Correction to: Detection of Epileptical Seizures Based on Alpha Band Statistical Features
}

\author{
Mustafa Sameer $^{1} \cdot$ Bharat Gupta $^{1}$ \\ Published online: 2 November 2020 \\ (c) Springer Science+Business Media, LLC, part of Springer Nature 2020
}

\section{Correction to: Wireless Personal Communications https://doi.org/10.1007/s11277-020-07542-5}

There were some errors in the citations and references in the initial online publication. The original article has been corrected.

The original article can be found online at https://doi.org/10.1007/s11277-020-07542-5.

\section{Mustafa Sameer}

mustafa.ec17@nitp.ac.in

Bharat Gupta

bharat@nitp.ac.in

1 Department of Electronics and Communication Engineering, National Institute of Technology Patna, Ashok Rajpath, Patna 800005, India 